\title{
BC emergency physicians declare emergency
}

$\mathrm{T}$ he ongoing overcrowding in British Columbia's emergency departments (EDs) has reached a crisis point, with physicians now calling for a \$10-million investment in solutions.

Between January 2010 and April 2012, 19 EDs received 40000 more patient visits than they were staffed to handle, according to data from $\mathrm{BC}$ health authorities.

"I come on at midnight and sometimes the first patient I see has been waiting there for six hours," says BC emergency physician Dr. David Haughton. "There's no telling who will explode. It's taking risks."

"We have no ability to do anything," adds Haughton. "It's not fair; it's not holding the people in control accountable."

Haughton is president of the British Columbia Medical Association's (BCMA) emergency medicine section, which represents emergency doctors in the province. He developed the remedial plan with the section and presented it to the BCMA Board of Directors on Feb. 8 . The board approved the plan, thus garnering the support of BC's 10000 doctors, Haughton says.

The plan to bring in more emergency physicians and tools to decrease wait times and increase government accountability was announced publicly on Feb. 23.

BC Minister of Health Margaret MacDiarmid stated in an email that the ministry has been in talks with emergency doctors and is committed to improving care in EDs, but "there is no new money available" to fund this new plan.

The proposed solutions, which include hiring more physicians and enforcing standards on how long a sick person has to wait for a bed, would cost $\$ 10$ million. The hiring costs would be added on to the $\$ 90$ million that the ministry has agreed to pay for all physician services from April 2012 through to March 2016. MacDiarmid says funds

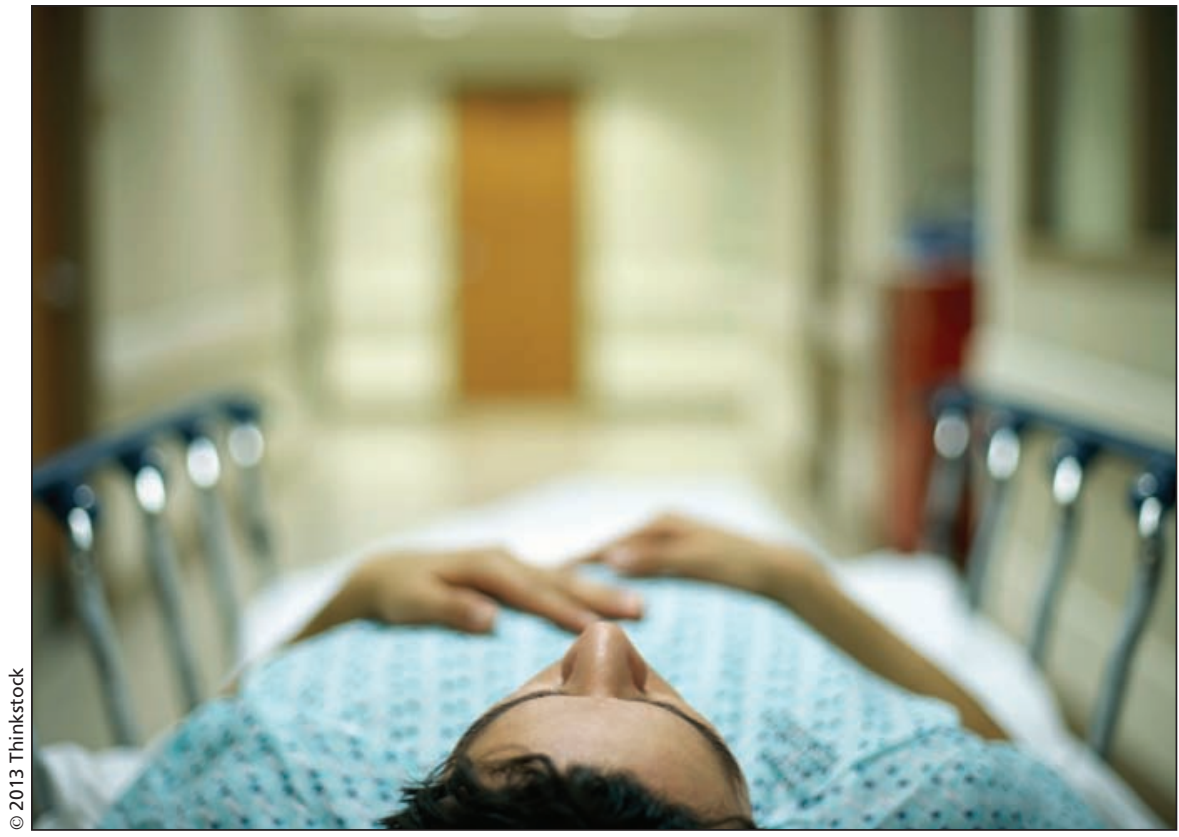

Overcrowding in emergency departments is, in part, the result of "access block" when patients wait on stretchers instead of being moved to in-patient care.

could be reallocated, but Haughton says money for the plan cannot come out of other priorities, but requires a new investment.

Overcrowding is, in part, the result of "access block" - when patients wait on stretchers in the ED instead of being moved to in-patient care. This prevents doctors from treating more incoming patients. Access block is the biggest issue facing EDs in $\mathrm{BC}$ and across Canada, according to the Canadian Association of Emergency Physicians.

Dr. Jodie Turner is an emergency physician at the East Kootenay Regional Hospital in Cranbrook, British Columbia, which, in a little over a year, has seen a $10 \%$ increase in patients while facing decreasing staff numbers.

She says she'll never forget coming in for a shift during the long weekend in February and within an hour facing a rapid succession of five serious cases, including trauma, stroke, chest pain and respiratory distress.

"Those five patients don't include everyone else in triage," she says. "I was the only emergency doctor work- ing." It isn't always this busy, but the issue of overcrowding is always there, she says.

There are two main schools of thought in $\mathrm{BC}$ when it comes to measuring ED needs and allocating funds.

The plan urges the province to adopt the workload model, which predicts how many staff are needed based on the volume of admitted patients and the level of care required. Under this model, most of the province's EDs would qualify for additional physicians.

The Alternative Payment Program (APP) provides additional funding only to those EDs that file a submission. That process, finalized in December, helps health authorities to identify where funding is needed the most, according to the ministry.

The Royal Inland Hospital ED in Kamloops, BC, is the only ED so far to qualify for additional funding under the APP.

"I'm very happy for the patients in Kamloops," Haughton says. "That's very good news for them, they needed it, but that means our patients didn't?" 
Since 2010, the BC Children's Hospital, where Haughton works, treated 8000 more patients than it was staffed to care for; the Kamloops ED treated 7000 more, Haughton says.

Approaches such as the workload model and the ensuing additional staff required would increase the cost of $\mathrm{ED}$ care, which is already the most expensive way to treat patients, according to MacDiarmid.

"Investing more and more money into emergency rooms is not a sustainable long-term solution," she said.
The key, she says, is to connect families with "general practitioners" so that they don't have to go to EDs. To this end, the government recently announced $\$ 132$ million for the "GP for Me, SVP" program. She says the ministry will also be announcing funding for community care.

Regardless of funding, emergency care is a necessity the government needs to prioritize, says Dr. Kevin McMeel. He's been working at the Regional General Hospital in Nanaimo, BC, for 22 years and has faced challenges like this before.
In 2004, the hospital's entire emergency department staff resigned their positions because of funding and staffing levels. Some stayed and treated patients for free during the four to six weeks it took before the government responded, he says.

"At that point, that was unsustainable as well and the government reassessed its priorities," he says.

"We've again reached that point." Juanita Bawagan, CMAJ

CMAJ 2013. DOI:10.1503/cmaj.109-4436 